\title{
La segunda generación de leyes archivísticas en México
}

Dra. Merizanda M.C. Ramírez-Aceves, Mexicana. merizanda@hotmail.com

Mtro. Ariel Sánchez Espinoza, Mexicano.

triariel@gmail.com

Facultad de Humanidades

Universidad Autónoma del Estado de México

Dr. Fernando Carreto Bernal, Mexicano.

fcarretomx@yahoo.com.mx

Facultad de Geografía

Universidad Autónoma del Estado de México

Recibido: 23 de agosto del 2020

Aceptado: 31 de enero del 2021

\section{Resumen}

En un artículo anterior se señalaron los Estados de la República Mexicana que diseñaron lo que denominamos como la primera generación de leyes archivísticas de este país por haberse creado antes de la publicación de la Ley Federal de Transparencia y Acceso a la Información Pública Gubernamental, estos fueron: Nayarit (1957), Puebla (1985), Estado de México (1986), Yucatán (1986), Tabasco (1987), Zacatecas (1987), Guerrero (1988), Veracruz (1990), Aguascalientes (1992), Chiapas (1993), Baja California Sur (1994), Sonora (1996), Jalisco (1998) y Quintana Roo (2001), que representaron tan sólo el 44\% del total de entidades federativas en contar con una ley de esta naturaleza. En contraste con lo anterior, fueron los Estados de Tlaxcala, Michoacán, Coahuila, Colima, Guanajuato, Hidalgo, San Luis Potosí, Distrito Federal (ahora Ciudad de México), Oaxaca, Querétaro y Morelos los que crearían de súbito en los últimos años lo que denominaríamos la segunda generación de leyes archivísticas, que quedarían insertas en el marco de las actuales políticas públicas referidas a la rendición de cuentas, la transparencia y el acceso a la información. Así pues, el objetivo de esta investigación es hacer un recorrido por estas leyes con el fin de observar su impacto en el ámbito de los archivos de este país.

Palabras clave: disposiciones legales - Leyes archivísticas - Archivos mexicanos 


\title{
The second generation of archival laws in Mexico
}

\begin{abstract}
In a previous article, the States of the Mexican Republic that designed what we call as the first generation of archival laws of this country because they were created before the publication of the Federal Law of Transparency and Access to Public Government Information, were: Nayarit (1957), Puebla (1985), State of Mexico (1986), Yucatán (1986), Tabasco (1987), Zacatecas (1987), Guerrero (1988), Veracruz (1990), Aguascalientes (1992), Chiapas ( 1993), Baja California Sur (1994), Sonora (1996), Jalisco (1998) and

Quintana Roo (2001), which represented only $44 \%$ of the total number of states in having a law of this nature. In contrast to the above, it was the States of Tlaxcala, Michoacán, Coahuila, Colima, Guanajuato, Hidalgo, San Luis Potosi, Mexico City (now Mexico City), Oaxaca, Querétaro and Morelos that would suddenly create in recent years what we would call the second generation of archival laws, which would be inserted within the framework of current public policies related to accountability, transparency and access to information. Therefore, the objective of this investigation is to make a tour of these laws in order to observe their impact in the field of the archives of this country.
\end{abstract}

Key words: Legal Provisions - Archival Laws - Mexican Archives

\section{Contexto general}

En el entorno de la sociedad de la información, el mundo necesita “ajustar sus marcos constitucionales con objeto de incorporar los nuevos derechos universales a la información". (Ackerman \& Sandoval, 2007). A pesar de la resistencia de muchos gobiernos por transparentar sus procesos administrativos, se comenzó desde hace un tiempo a vislumbrar el diseño y promulgación de disposiciones tendientes a legalizar los procesos de transparencia y acceso a la información en diversas latitudes. En un reporte publicado por Privacy International titulado Freedom of Information around the World 2006 (Banisar, 2006), se mostraba un estudio para determinar que 69 países habían publicado hasta ese momento leyes de transparencia y acceso a la información. Sorprendentemente, casi un 50\% 
de ellas habían entrado en vigor a partir del año 2000, lo que reflejaba una irrupción abrupta en este contexto a inicios del siglo XXI. Hoy en día, podemos contar más de 112 países que se han sumado a este colectivo de acuerdo con datos del Global Right to Information Raiting de 2018 posicionando la ley de México en el lugar número séptimo tras una evaluación de su contenido. (Centre for Law and Democracy, 2018)

Las demandas sociales de acceso a la información pública, han dado lugar incluso a la promulgación de leyes en materia de Archivos, derivado de la importancia que han adquirido los documentos administrativos en los últimos años, en contraste con el secretismo que reinaba en épocas pasadas. Estas disposiciones promueven el acceso a los documentos que respaldan las decisiones políticas, lo que supone una transformación profunda de la función social de los Archivos.

Actualmente, en los países iberoamericanos se reconoce el valor de los documentos como un medio para fomentar la identidad nacional y para establecer sociedades más informadas. La mejor ley de transparencia y acceso a la información pierde todo sentido si no existen documentos que consultar o si éstos se encuentran en tal desorden que la rendición de cuentas se vuelve inexistente.

Es verdad que las leyes por sí mismas no representan una garantía para el ejercicio de este derecho, hace falta echar una mirada al pasado para hacer conciencia de las vicisitudes por las que han pasado los Archivos y observar de cerca las condiciones tan lamentables en las que se encuentran sus documentos y el lugar que ocupan en la jerarquía de la Administración Pública.

Es curioso observar cómo países latinoamericanos como México que ha creado hace cerca de dos décadas una ley de transparencia y de acceso a la información, tiene una precaria tradición en cuanto a gestión de documentos se refiere, en contraste con otros países.

El rápido proceso de publicación de un marco legal en México que garantizara no sólo la rendición de cuentas sino la transparencia y el acceso a la información, fue consecuencia muy probablemente de diversos factores, entre los que se podrían mencionar la proliferación repentina de nuevos regímenes democráticos; de la presión que ejercieron las 
instituciones financieras internacionales para que los países promulgaran este tipo de leyes; del robustecimiento que tuvieron las asociaciones regionales de libre comercio; del gran apogeo que ha tenido en los últimos tiempos las tecnologías de la información y comunicación (TIC's); del impulso a las agendas anticorrupción que buscaban elevar la calidad de las Administraciones Públicas en diversas Naciones del mundo y de la implementación de estrategias de legitimación de nuevos gobierno, entre otros.

Esta vez, su contenido distaría del de la primera generación, pues ahora su objetivo estaría centrado básicamente en regular la administración, manejo, resguardo y coordinación ya no sólo de los Archivos y documentos históricos de interés público, sino también de los administrativos, pertenecientes a los tres poderes de gobierno y fomentar así su consulta.

Se comenzaron también a considerar conceptos y definiciones propios tanto del vocabulario archivístico, como del derecho a la información. Se incluyó por primera vez el término sujeto obligado para referirse a las instituciones a las que la ley les exigía rendir cuentas a la sociedad y transparentar sus procesos administrativos. Se comenzó a hablar de la manera en que debían gestionarse los documentos y los mecanismos para su valoración. Se amplió la estructura del Sistema Estatal y, en consecuencia, su funcionamiento. Se delinearon los criterios de acceso a la información y se establecieron sanciones para quienes incumplieran estos preceptos.

\section{La Ley Estatal de Archivos en Tlaxcala}

En la ley de Tlaxcala (H. Congreso del Estado de Tlaxcala, 2003) se incluyeron conceptos como archivo, documento, entidad pública y servidor público. Al primero se lo definió como "el lugar donde se encuentran organizados y reunidos los documentos generados por las entidades públicas" (art. $3^{\circ}$ ), entendidas éstas como "las dependencias y entidades de los poderes del Estado, organismos públicos autónomos y gobiernos municipales" (art. $2^{\circ}$ ). Quedaba claro que el Archivo debía ser entendido como la institución de resguardo de los documentos y no como el contenido documental, por lo que el conjunto de estos, sea cual fuera su fecha, su forma y soporte material, acumulados en un proceso natural por una persona o institución pública o privada en el transcurso de su gestión, 
conservados, respetando aquel orden, para servir como testimonio e información para la persona o institución que lo produce, para los ciudadanos o para servir de fuentes de historia, tantas veces proclamado por los especialistas quedaba fuera de este contexto.

En cambio, al documento se lo concibió como el registro de información contenido en un soporte, sin importar la estructura material en la que se haya generado, que podía ser utilizado como prueba, toma de decisiones o consulta. El documento electrónico por primera vez era considerado en una ley.

En cuanto al tipo de Archivo también fue primicia el establecimiento por vía legal de los de Trámite, de Concentración e Históricos, cuyas funciones serían básicamente las consideradas en el tratamiento documental (identificación, clasificación, ordenación, valoración, selección, eliminación, descripción y transferencias), además de la promoción, organización y coordinación de cursos de capacitación sobre archivística.

\section{La Ley Estatal de Archivos en Michoacán}

Al siguiente año, Michoacán (H. Congreso del Estado de Michoacán, 2004) publicaría su ley con algunas variantes que la de Tlaxcala. Incluyó también algunos conceptos, entre los que destacaron por ser objeto de estudio de la archivística el de administración de documentos, archivos, archivo de trámite, archivo de concentración, archivo histórico, archivo privado, documento y patrimonio documental, y cuyas definiciones no diferirían de las que ya se habían mencionado en los textos publicados hasta ese momento.

Lo que sí llamaba la atención era que a pesar de que la intensión de las leyes de transparencia, en términos generales, establecían la consulta de los documentos, ya sean estos administrativos o históricos, la ley de archivos michoacana restringía para uso exclusivo de los servidores públicos los primeros, hasta antes de la promulgación de su propia ley de transparencia, en tanto que de los segundos el acceso sería invariablemente público.

En este documento se resaltaba el acuerdo de que los documentos debían ordenarse en función del principio de procedencia, aspecto que hasta ese momento no había considerado ninguna otra ley. Por primera vez también, se establecía un periodo de un año 
para la conservación de los documentos en los Archivos de Trámite y de doce en los de Concentración.

Al igual que otras leyes se mencionaba el tratamiento de los documentos que incluía las tareas de identificación, clasificación, catalogación, valoración y depuración, contando para este último aspecto, con la asesoría de personal especializado de los Archivos de Concentración e Históricos. Asimismo, se hablaba de la preservación o restauración y difusión tan sólo para el caso de estos últimos. Se incluía también la elaboración de instrumentos de descripción que para el caso de las dos primeras fases del ciclo vital, serían el Catálogo de vigencia de los documentos e inventarios generales y para la última fase, índices y catálogos más detallados, cuya actualización debía hacerse de manera bianual.

De igual forma, se estipulaba la configuración del Sistema Estatal de Archivos integrado por una Asamblea General y un Comité Técnico. La primera se conformaría por los responsables de todos los Archivos, en tanto que el segundo, por un representante de cada uno de los poderes del gobierno local, tres representantes de los Ayuntamientos, dos de los Organismos Autónomos Públicos y dos de los Archivos privados. Los siguientes dos años transcurrieron sin que ningún Estado mostrara señales de haber publicado ley alguna en la materia, empero en 2007 Coahuila, Colima, Guanajuato, Hidalgo y San Luis Potosí serían las Entidades más próximas en irrumpir ese silencio al mismo tiempo.

\section{La Ley Estatal de Archivos en Coahuila}

En la ley de Coahuila (H. Congreso del Estado de Coahuila, 2007) se incluía un catálogo bastante extenso de algunos conceptos, entre los que destacaban el de administración de documentos de interés público, archivo, archivo general, archivos públicos, archivos de gestión o trámite, archivos de concentración, archivos históricos, bibliotecas, centros de documentación, centros de información, Comité Técnico de documentación, Comisión dictaminadora, documento, documentos de interés público, hemeroteca, mapotecas, entre otras, los cuales tampoco aportaron nada nuevo, con excepción de la inclusión de términos que hasta entonces no se habían considerado en las leyes anteriores. 
Se hizo énfasis en que cada Sujeto obligado ${ }^{1}$ debía establecer sus propios Archivos. A pesar de que se pedía que los documentos se inventariasen con base en el formato con que contaran las instituciones, con el fin de garantizar su control, propiedad y utilidad pública, la ley no aludía a otras tareas.

En otro apartado se integraba el Sistema Estatal de Documentación, que no de Archivos, tal y como lo señalaban otras leyes. Éste estaría compuesto por los Archivos de Trámite, Concentración e Históricos, Bibliotecas, Centros de Documentación, Hemerotecas, Mapotecas, Centros de Información, Unidades que resguardaran documentos audiovisuales, de Correspondencia, de Microfilmación, de Reprografía, de Cómputo y Nuevas Tecnologías, los Archivos Municipales, los de las Universidades Públicas, los de los Partidos Políticos y de todas aquellas que por la naturaleza propia de sus funciones fuera necesario crear. Además, para el cumplimiento de sus objetivos, existía un Comité Técnico.

Por su parte, el Archivo General del Estado fungía como órgano desconcentrado y tenía como principal propósito normar, regular y preservar acervos, expedientes, registros y en general, todos aquellos documentos administrativos e históricos de los tres poderes del gobierno local. Se creaba también una Comisión de depuración y eliminación de documentos que decidía sobre la conservación temporal o permanente de estos, incluyendo una acuciosa descripción sobre la metodología a seguir para este proceso. Al respecto, se estableció un plazo de treinta años, contados a partir de su generación, para decidir el destino final de los

\section{La Ley Estatal de Archivos de Colima}

Por su parte, Colima (H. Congreso del Estado de Colima, 2009) representó un caso particular, puesto que fue el primer Estado en emitir primero una ley de transparencia y tres años después una de Archivos, por lo que era de esperarse que esta última se ajustara a los lineamientos que se establecieran en aquella, sin embargo, esto no ocurrió así, pues a pesar de que la ley de transparencia señalaba que la información en poder de las entidades públicas

\footnotetext{
${ }^{1}$ Áreas o unidades que constituyen a las distintas Dependencias y Entidades del Ejecutivo, Legislativo y Judicial, los Municipios, las Escuelas y Universidades Públicas, Partidos Políticos y cualquier otro organismo público o privado. 
estaría a disposición de las personas, salvo la que se considerase confidencial o reservada, en la ley de Archivos se reservaba para uso exclusivo de los servidores públicos la que obrase en los Archivos de Trámite y Concentración.

Se estipularon tareas de tratamiento documental, tales como identificación, ordenación, clasificación, descripción y selección, las cuales incluso se debían aplicar a los documentos electrónicos. En cuanto a los plazos de retención, en esta Entidad variaban en comparación con otras, ya que se designó un periodo de cinco años para la conservación de los documentos en el Archivo de Trámite y de veinticinco en el de Concentración, con lo cual, transcurridos treinta años, los documentos que adquirieran valores secundarios podrían remitirse a los Archivos Históricos del Ejecutivo y del Legislativo, puesto que el Poder Judicial debía establecer sus propios plazos de vigencia.

Se constituyó de igual manera, el Sistema Estatal de Archivos integrado por un Comité Estatal, un Órgano de Regulación y por Comités Técnicos. Finalmente, se hizo especial hincapié en la conservación óptima de los documentos y de los sitios en lo que estos se resguardaran, así pues, se debían combatir los factores y agentes de deterioro, aplicar medidas preventivas que incluían la iluminación, ventilación y mobiliario.

\section{La Ley Estatal de Archivos en Guanajuato}

Como hemos mencionado, Guanajuato (H. Congreso del Estado de Guanajuato, 2007) también impulsó su disposición en el año 2007 bajo circunstancias similares a las de Colima, puesto que su ley de transparencia también antecedió a la de Archivos.

Incluyó un vasto glosario de términos que contenía algunas novedades, tales como archivística, catálogo de disposición documental, conservación, cuadro general de clasificación archivística, destino, documentos electrónicos, fondo documental, inventarios documentales y plazo de conservación, así como los ya tradicionales administración de documentos, Archivo General del que se consideraron parte los Archivos de Trámite, de Concentración e Históricos, documentos de archivo, que de igual manera contenían a los documentos activos, semiactivos e inactivos. 
Se estableció que los instrumentos de control y consulta que debían elaborar los Archivos eran el Cuadro General de Clasificación Archivística, el Catálogo de Disposición Documental e Inventarios documentales. Asimismo, se mencionó la existencia de un Sistema Estatal de Archivos Generales.

\section{La Ley Estatal de Archivos en Hidalgo}

Hidalgo (H. Congreso del Estado de Hidalgo, 2007) fue otra Entidad que generó su ley en el mismo año. Esta vez, los términos incluidos en su glosario cambiarían un poco, pues destacaron conceptos como el de archivo, cuyo sentido esta vez asumía, además del propuesto en la ley tlaxcalteca, el de ser concebido como contenido y no sólo continente, su definición se expresó de la siguiente manera "el conjunto de documentos producidos o recibidos por cualquier individuo, familia, los Poderes, las Dependencias, Entidades y Organismos, tanto públicos como privados, en el desarrollo de sus actividades, que se conservan de forma organizada, para servir inicialmente como prueba y después como fuente de información general; así como las instituciones archivísticas y los locales en donde se guardan los documentos". (art. $4^{\circ}$ ); archivo y documento electrónico, Catálogo de Disposición Documental, ciclo vital, Cuadro General de Clasificación, guía de archivo, inventarios documentales, patrimonio documental, Sistema Estatal de Archivos, Sistema integral de Archivos y valor documental.

Tal y como ocurrió en Colima, en la ley hidalguense también se señaló que los documentos contenidos en los Archivos de Trámite y de Concentración serían de uso restringido para los servidores públicos. En este documento se establecieron once principios bajo los cuales se regularía la actividad archivística, a saber: $\left(\operatorname{art.} 11^{\circ}\right)$

- Organización: Disponer de los documentos organizados, con el objeto de que la información institucional sea recuperable para su uso en el servicio que los sujetos obligados proporcionan a la ciudadanía como fuente histórica.

- Obligatoriedad archivística: el Estado garantiza la creación, organización, preservación y control de los servicios archivísticos, tenido en cuenta los principios 
de procedencia y orden original, el ciclo vital de los documentos y la normatividad archivística.

- Accesibilidad: Promover la participación ciudadana en la consulta del patrimonio documental, garantizando el derecho a la información previsto por la Ley correspondiente.

- Imprescindibilidad: Los documentos que conforman los archivos son imprescindibles para la toma de decisiones basadas en antecedentes. Pasada su vigencia, estos acervos pasan a constituir el patrimonio cultural y la identidad Estatal y Nacional.

- Institucionalidad e instrumentabilidad: Los documentos institucionalizan las decisiones administrativas y los archivos constituyen una herramienta indispensable para la gestión y evaluación administrativa, económica, política y cultural del Estado y la Administración de Justicia.

- Responsabilidad: Los servidores públicos son responsables de la clasificación, ordenación, conservación, uso y manejo de los documentos.

- Coordinación: El Órgano rector, a través del Sistema Estatal de Archivos es el encargado de orientar y coordinar la función archivística para coadyuvar a la eficacia de la gestión y salvaguardar el patrimonio documental y cultural del Estado.

- Administración: Es una obligación del Estado la administración de los archivos públicos, en virtud de que en ellas se fincan las bases ejecutivas y operativas de los Programas Públicos Gubernamentales.

- Racionalidad: Los archivos actúan como elementos fundamentales de la racionalidad de la Administración Pública y como agentes dinamizadores de la acción Estatal.

- Modernización: El Estado propugnará por el fortalecimiento de la infraestructura y la organización de sus sistemas de información, estableciendo programas eficientes y actualizados de administración de documentos y Archivos.

- Imprescriptibilidad: Los Archivos tienen una función probatoria de la gestión pública, garantizando su existencia documental.

Por otra parte, se estableció una clasificación para los Archivos, la cual se basaba tanto en la aplicación del ciclo vital de los documentos, como en la naturaleza de la propia información. Para la primera, se establecieron Unidades Centrales de Correspondencia, 
Archivos de Trámite, de Concentración e Históricos, en tanto que para la segunda, la información sería pública, reservada y confidencial.

La Unidad Central de Correspondencia debía ser la oficina responsable de la generación, recepción, seguimiento y control del manejo de la correspondencia de entrada y salida, en donde por funciones y atribuciones debería intervenir en la gestión de los Sujetos Obligados. $\left(\operatorname{art} .19^{\circ}\right)$.

El Archivo de Trámite, en cambio, tendría la responsabilidad de recibir, clasificar, abrir expedientes, glosar, catalogar, expurgar, valorar y realizar transferencias primarias de los documentos de uso cotidiano y necesario para el ejercicio de las atribuciones de la Unidad Administrativa, los cuales se deberían conservar según lo que se dispusiera en el Catálogo de Disposición Documental. (art. 20)

Por su parte, el Archivo de Concentración debía ser la unidad responsable de recibir transferencias primarias, archivar, prestar y depurar los documentos que hubieran concluido su vida útil administrativa, legal y fiscal. (art. 21ํ) Finalmente, el Archivo Histórico se encargaría de organizar, conservar, administrar, describir y divulgar la memoria documental. $\left(\right.$ art. $\left.22^{\circ}\right)$

En cuanto a los instrumentos de descripción a elaborar por los Sujetos Obligados, se dispuso que éstos fueran el Cuadro General de Clasificación Archivística, el Catálogo de Disposición Documental, la Guía de Archivo Documental e Inventarios Documentales. Por último, se establecería la configuración del Sistema Estatal de Archivos, que se integraría por un Consejo Estatal de Archivos, por un Órgano Rector y por Comités Técnicos.

\section{La Ley Estatal de Archivos en San Luis Potosí}

San Luis Potosí (H. Congreso del Estado de San Luis Potosí, 2007) sería la última Entidad federativa en emitir al mismo tiempo la Ley de Transparencia Administrativa y Acceso a la Información Pública, la Ley de Protección de Datos Personales, la Ley de Archivos Administrativos y la Ley de Archivos en el año 2007, reunidas en un mismo cuerpo normativo, que tendría por objeto garantizar el ejercicio del derecho de acceso a la 
información pública; proteger los datos personales, contribuir a la rendición de cuentas, regular la administración de los Archivos, preservación y difusión del patrimonio documental y promocionar una cultura de transparencia, entre otros aspectos.

El derecho a la información en el entorno potosino no pasaba de ser entendido como un tema meramente doctrinal, puesto que ni en su propia Constitución se legislaba sobre ello. Sin embargo, como consecuencia de la pronta emisión de disposiciones, no sólo federales, sino también de las que generaron otros Estados, San Luis Potosí se dio a la tarea de contrarrestar esta ausencia consciente de los límites que la seguridad pública y el derecho a la privacidad de los particulares imponía.

Así, el derecho de toda persona a acceder a la información sobre sí misma o sobre sus bienes y el control sobre los documentos generados y recibidos por las instituciones, en poco tiempo serían aspectos que se convertirían en los puntos neurálgicos sobre los cuales legislar.

La configuración de una Comisión Estatal de Garantía de Acceso a la Información Pública (en adelante CEGAIP) y de un Sistema Estatal de Documentación y Archivos, dependiente de la Comisión, serían el primer paso para la consolidación de las políticas públicas en esta demarcación.

Al igual que el resto de las leyes, en esta se incluyó también un glosario de términos bastante extenso en el que destacaron el de administración documental, Archivo, Archivo de Trámite, Archivo de Concentración, Archivo Histórico, Catálogo de Disposición Documental, documento, información confidencial, reservada, pública y pública de oficio y unidad de información pública, así como Constitución, Comité de información, derecho de acceso a la información pública, entes obligados, entidades públicas, indicadores de gestión, interés público, protección de datos personales, prueba de daño, servidores públicos, solicitante y versión pública.

Su fundamento principal fue la atención a los principios de máxima publicidad, disponibilidad y gratuidad de la información, con el objeto de facilitar ésta a cualquier persona que la solicitara. 
Se mencionaba de igual manera, la actualización del Catálogo de Disposición Documental de cada dependencia por lo menos cada veinticinco días hábiles.

Asimismo, se detallaba la información que cada institución del Estado y sus municipios debía hacer pública, preferentemente a través de medios electrónicos y de acuerdo con los lineamientos que el CEGAIP emitiera, al tiempo que establecía los criterios para clasificar aquella que debía ser reservada.

En relación con el Sistema Estatal de Documentación y Archivo se establecía como una unidad administrativa responsable de administrar y sistematizar los documentos y la información en ellos contenida que estuviera en posesión de las entidades públicas, así como dictar los lineamientos y criterios técnicos para organizar, administrar y resguardar los Archivos de toda índole.

Al respecto se estipuló que una vez concluida la vigencia administrativa de los documentos, éstos pasarían del Archivo de Trámite al de Concentración en donde se resguardarían por un periodo de diez años para ser transferidos posteriormente al Archivo Histórico, o bien, destruirse previo dictamen y autorización de las instancias correspondientes. Por su parte, serían el Distrito Federal (ahora Ciudad de México) y Oaxaca las penúltimas Entidades que emitirían su ley de Archivos en el año 2008.

\section{La Ley de Archivos en el Distrito Federal}

La ley del Distrito Federal (Asamblea del Distrito Federal, 2008) incluyó de igual manera, una serie de términos similares a las otras disposiciones, sólo que esta vez mostraba algunas novedades, pues además de los ya tradicionales Archivo, Catálogo de Disposición Documental, Cuadro General de Clasificación Archivística, documento electrónico, expediente, fondo, información, inventarios documentales, patrimonio documental, sección y serie, también se definieron conceptos como el de baja documental, disposición documental documento de archivo, clasificación archivística, conservación preventiva, descripción documental, destino, gestión documental, plazo de conservación, procesos archivísticos, transferencia, valor documental, valores primarios y valores secundarios. 
Tal y como lo hizo el Estado de Hidalgo, la ley defeña aludió al cumplimiento de los principios de orden original y de procedencia, pero además incluyó otros hasta ahora no establecidos en otras leyes, a saber, el de integridad y el de preservación. En cuanto al principio de integridad se consideró responsabilidad de los entes públicos, mantener organizados los documentos para su fácil localización, consulta y reproducción, utilizando métodos y técnicas para la sistematización de la información, así como de la tecnología para la administración de los propios documentos.

En relación con el principio de integridad se manifestó como una de las principales responsabilidades de los mismos entes públicos, la manutención de los documentos en perfecto estado de conservación, evitando en todo momento, su destrucción, deterioro o alteración alguna.

Se estableció un Sistema Institucional de Archivos que se conformaría con los Archivos de Trámite, de Concentración e Históricos de cada organismo público y constaría de componentes normativos y operativos. Los primeros tendrían a su cargo la regulación y coordinación del sistema, en tanto que los segundos serían los propios Archivos encargados de su funcionamiento.

Los componentes normativos estarían dados a través de una Unidad Coordinadora de Archivos y de un Comité Técnico Interno de Administración de Documentos, mientras que los operativos por Unidades Generales del ente público (unidad central de correspondencia, unidad de Archivo de Concentración y unidad de Archivo Histórico) y Unidades Particulares de cada Área Administrativa (unidad de documentación en trámite y unidad de Archivo de Trámite).

Como parte de los procesos archivísticos que los organismos públicos debían llevar a cabo, se establecieron los siguientes:

- Manejo de la correspondencia de entrada, control de correspondencia en trámite y correspondencia de salida

- Integración de expedientes y series documentales 
- Clasificación y ordenación de expedientes

- Descripción documental

- Valoración primaria y secundaria

- Disposición documental

- Acceso a la información archivística

- Transferencias primarias y secundarias

- Conservación y restauración

- Difusión

Se estableció que los instrumentos de descripción que debían elaborarse, serían, además del Catálogo de Disposición Documental y del Cuadro General de Clasificación Archivística, un calendario de caducidades, inventarios de Archivos de Trámite, Concentración e Históricos, inventarios de transferencia primaria y secundaria, Guía General de Fondos de los Archivos Históricos, inventarios de baja o depuración, controles de correspondencia de entrada y salida, controles de préstamos de expedientes y estadísticas de usuarios, mapas de ordenación topográfica de los acervos de Concentración e Históricos, así como controles de conservación y restauración de documentos.

Se acordó también, la elaboración de programas institucionales de desarrollo archivístico anuales, que debían incluir proyectos y acciones de instrumentación normativa, de capacitación y especialización del personal, de adquisición de recursos materiales, de incorporación de tecnologías de información, de difusión y divulgación archivística, de conservación y preservación de la información y de planes preventivos que permitieran enfrentar situaciones de emergencia, riesgo y catástrofes.

Lo que también se consideró en esta ley fue el equipo con que debían contar los Archivos, entre los que destacaron detectores de humo, extintores de fuego de gas inocuo, 
materiales de archivo retardantes, salas de desinfección, salas de desinsectación, vigilancia y planes de emergencia.

\section{La Ley Estatal de Archivos en Oaxaca}

Oaxaca (H. Congreso del Estado de Oaxaca, 2008) seguiría en la lista de los Estados preocupados por la emisión de leyes de esta naturaleza. Como venía siendo una costumbre, su glosario incluyó términos ya considerados en las anteriores disposiciones legales.

También habló sobre la responsabilidad que asumiría cada uno de los Archivos y las funciones que llevarían a cabo sus responsables. De los instrumentos de descripción se dijo poco, tan sólo que éstos debían ser el Catálogo de Disposición Documental, el Cuadro General de Clasificación Archivística e inventarios documentales.

Se dispuso la configuración de un Sistema de Archivos que debía incluir tareas poco profusas, tales como los procesos para el registro o captura, la clasificación por funciones, la descripción a partir de sección, serie y expediente, así como la preservación, uso y disposición final de los documentos. A pesar de que se establecieron las facultades y obligaciones de los Archivos Generales, no se los definió a éstos.

Se estableció que cada expediente debía contener una portada con elementos mínimos de identificación, tales como Unidad Administrativa, fondo, sección, serie, número consecutivo de expediente, fechas de apertura y cierre, asunto, valores documentales, vigencia documental y número de fojas útiles.

Esta ley definía un Sistema Estatal de Archivos concebido como un conjunto de mecanismos de coordinación, cooperación y concertación a través de los cuales se interrelacionarían los Archivos no sólo del Estado, sino de sus propios municipios. Este Sistema estaría integrado por un Consejo Estatal de Archivos, un Comité Técnico, un Coordinador y los responsables de los Archivos. Finalmente, en los Estados de Querétaro y Morelos se instaurarían más recientemente leyes que regularían el control de sus Archivos. 


\section{La Ley Estatal de Archivos en Querétaro}

En la ley queretana (H. Congreso del Estado de Querétaro, 2009) se creaba el Sistema Estatal de Archivos con el propósito de garantizar el manejo uniforme e integral de los procesos archivísticos de su propio entorno, conformándose por una Comisión Estatal de Archivos, una Dirección, Comités Técnicos, Unidades de Concentración de los poderes, municipios y dependencias de la Administración Pública y por los Archivos de Trámite ubicados al interior de las instituciones. Además, se especificaban las funciones que cada uno de estos organismos debía desempeñar.

El Sistema incluyó, además de los procesos para el registro o captura, la clasificación por funciones, la descripción a partir de sección, serie y expediente y la preservación, el uso y disposición final de los documentos, lo que se consideró el Registro Estatal de Archivos que consistía en ser un instrumento catastral cuyo fin era registrar, difundir y proteger el patrimonio documental, así como llevar la cuenta de los Archivos y documentos que se insertarían en él.

En este texto, por primera vez se concibió al Archivo General del Estado, como "el lugar en donde se lleva a cabo la guarda, conservación, descripción especializada, investigación y difusión de la memoria documental que...debe almacenarse para consulta esporádica o simple depósito". (art. 18) Éste era considerado un sitio público en el que se debían resguardar los testimonios documentales que registraran los hechos, actos administrativos, jurídicos, fiscales o contables, que fueran creados, recibidos, manejados y usados en el ejercicio de las facultades de las entidades gubernamentales. Se estableció para ellos una clasificación alfanumérica y topográfica.

Un aspecto que llama la atención por la novedad del término, fue la inclusión de los denominados Archivos registrales, que aunque no se explicaba por ninguna parte en qué debían consistir, aparecieron enumeradas las instituciones que adoptarían esta condición. Estas eran el Archivo del Registro Público de la Propiedad y del Comercio, el Archivo General de Notarías, el Archivo del Registro Civil y el Archivo del Registro de instrumentos jurídicos de la Dirección Jurídica y Consultiva de la Secretaría de Gobierno del Estado. 
El Archivo Histórico, por su parte, se estableció como la institución en la que se debía llevar a cabo la "guarda, conservación, descripción especializada, investigación y difusión de la memoria documental de las entidades gubernamentales...que se considere patrimonio histórico del Estado". (art. 24)

En cuanto a la manera de administrar los documentos, se estableció que éstos debían ser valorados ante todo, mediante los procedimientos que se emitieran para ello, dejando en claro sus valores primarios y secundarios. Para el control de los documentos, quedaba establecida la aplicación del principio de procedencia, que como se sabe, consiste en mantener agrupados los documentos procedentes de un mismo organismo, sin mezclarlos con otros. Además de ello, se mencionaba que los documentos quedaban sujetos a observar los principios de disponibilidad, eficiencia, localización expedita, integridad y conservación, a pesar de que nunca llegaron a definirse.

El Catálogo de vigencia de documentos, el Cuadro General de Clasificación Archivística y los inventarios documentales, se establecieron como los principales instrumentos de descripción a elaborar. Del primero se mencionó que serviría de base para la depuración de los documentos ubicados en los Archivos de Trámite y Concentración. Los datos que debía consignar eran los criterios sobre la conservación y vigencia documental, los plazos de conservación, los valores, la clasificación -reservada o confidencial- y el destino final.

Al Cuadro General de Clasificación Archivística se lo definió como el “instrumento técnico y de consulta que refleja la estructura de un Archivo, con base en las atribuciones de cada entidad gubernamental y su proceso de identificación y organización sistemática de los documentos de archivo en categorías, de acuerdo con esquemas lógicos previamente establecidos, métodos y reglas determinados". (art. $45^{\circ}$ )

Se estableció que para su elaboración era necesario elaborar inventarios documentales como instrumento de consulta en el que debían describirse las series y expedientes de un Archivo, permitiendo con ello su localización, transferencia o baja definitiva. 
En el texto se mencionaba también que la Dirección Estatal de Archivos debía adoptar, instrumentar y evaluar programas de conservación y mantenimiento físico de sus acervos y en los que se debían prever normas, condiciones, medidas y procedimientos necesarios para combatir y evitar su deterioro.

\section{La Ley Estatal de Archivos en Morelos}

Finalmente, fue el Estado de Morelos (H. Congreso del Estado de Morelos, 2009) el que se formó al final de la fila para crear su ley, conscientes de que la generación de información creada por las instituciones sin la existencia de un sistema archivístico eficaz imposibilita la capacidad de rendir cuentas y garantizar con ello el derecho de acceso a la información pública.

Como el resto de las leyes, la morelense incluyó un glosario en el que se consideraron términos que no mostraron grandes novedades, con excepción de las definiciones otorgadas a lo que se denominó Catálogo general de información archivística y Formato para la identificación de información clasificada.

Al primero se lo definió como el "instrumento técnico que refleja la estructura de un Archivo con base en los criterios emitidos por el Sistema Estatal de Documentación y Archivo". Si la estructura se refiere a los fondos documentales que se encuentran en los Archivos, entonces lo que se quizá se intentó definir fue la guía que es el instrumento de descripción que atiende esta necesidad.

Al segundo se lo precisó como el "documento que establece los valores documentales, los plazos de clasificación, la clasificación de reserva o confidencialidad...”, es decir, lo que para la archivística sería el Calendario de conservación o el Cuadro General de Clasificación Archivística como lo han denominado las leyes descritas anteriormente. 
Artículos más adelante, se establecieron que todos los Archivos públicos debían formar parte del Sistema Estatal de Documentación, el cual estaría coordinado por el Instituto Estatal de Documentación de esta Entidad.

El Sistema Estatal de Documentación y Archivos fue fijado como "el conjunto de elementos que integran tanto el acervo documental del Estado, como el conjunto de normas, reglamentos y lineamientos que aseguran su sistematización, administración, resguardo y conservación archivística y otras unidades administrativas”. (art. 17º)

En cuanto a la administración de documentos, destacaron aspectos importantes, tales como la manera en que debían registrase éstos a fin de mantener un control; su depuración considerando la importancia y el valor; los responsables de elaborar inventarios y calendarios de vigencia; la retención de los documentos por un periodo de hasta treinta años antes de ser valorados; los procedimientos para destruirlos y los mecanismos para la conservación de aquellos que formarán parte permanentemente de la memoria histórica morelense.

Por otro lado, se dispuso un sistema de control archivístico fundamentado en Archivos de trámite, de concentración e histórico, señalando que por razones presupuestales, los primeros y el último debían establecerse en la misma unidad administrativa. Fue ésta la primera ley que fijó las funciones de cada uno de los Archivos del sistema. Así, el Archivo de Trámite debía tener las siguientes obligaciones: (art. 27)

- Determinar los criterios para integrar los expedientes del Archivo.

- Conservar los catálogos de los documentos activos y turnar a la Unidad de Información Pública el catálogo de aquellos que hubieran sido clasificados como reservados o confidenciales.

- Emitir anualmente el inventario correspondiente.

El Archivo de Concentración debía atender lo relativo a: (art. 28) 
- Recibir los catálogos de los documentos activos procedentes de los Archivos de trámite.

- Elaborar y conservar los catálogos de los documentos activos hasta cumplir con los plazos establecidos en el Catálogo General de Información, o bien, hasta que hubiesen cumplido su periodo de reserva.

- Solicitar la liberación de los expedientes para determinar su transferencia secundaria.

Finalmente, se dijo del Archivo Histórico que sus funciones serían las siguientes: (art. 30)

- Coadyuvar en la elaboración del Cuadro General de Clasificación Archivística, el Catálogo de Disposición Documental y los inventarios documentales.

- Valorar los documentos que deban conservarse permanentemente.

- Recibir los documentos con valor histórico.

- Establecer programas que permitan la conservación de los documentos en soportes electrónicos.

- Definir los criterios de conservación.

- Aprobar los catálogos de transferencias secundarias.

- Elaborar dictámenes y catálogos de baja documental.

- Difundir el patrimonio documental del Estado.

En cuanto a los instrumentos de descripción no mostraron variaciones con relación a los mencionados en el resto de las leyes, salvo que para el caso del Cuadro General de Información Archivística se estableció que su estructura debía atender un criterio jerárquico basado en el fondo en primer lugar, la sección en segundo y la serie en tercero. 
Por otro lado, para identificar a los expedientes se estableció que la portada debía contener algunos datos como el fondo, la sección, la serie, la unidad administrativa de procedencia, un número de expediente que para este caso sería consecutivo, el asunto, las fechas extremas, la vigencia administrativa y el número total de fojas, así como la leyenda de "clasificado", "reservado" o "confidencial" para aquellos casos considerados bajo estas categorías. Se mencionaron también las medidas a observar cuando se tratara de documentos electrónicos que incluyeron la sistematización, la digitalización y la migración de soportes.

Esta ley mostró un plazo de conservación de los documentos distinto al de las otras, puesto que señalaba que a partir de la desclasificación de aquellos que la hubieran adquirido, se adicionaría un periodo igual al que tuvieron cuando se consideraron como reservados. En tanto que los que hubieran sido objeto de solicitudes de acceso se conservarían por cinco años más a partir de la culminación del plazo natural.

Asimismo, se mencionó que para lograr una adecuada gestión de los documentos, sería necesario contar con tres elementos fundamentales: 1. Espacios destinados a la recepción, organización y resguardo de estos, 2. Sistemas de control ambiental y de seguridad e 3. Infraestructura idónea para garantizar su resguardo íntegro. En esta ley se favoreció la creación de Archivos regionales municipales, incluso se mencionó la configuración de un Archivo histórico municipal para el Estado morelense.

Un aspecto no menos importante fue la inclusión de alguna tipología documental que debía conservarse en el Archivo de gestión por plazos determinados previamente, tal y como se muestra en el siguiente Cuadro:

\section{Instancia Tipología documental Plazo de vigencia}

Ayuntamientos Actas de cabildo $\quad 6$ años


Poder legislativo Auditorias 6 años

Actas de sesiones del pleno

Propuestas de reforma

Iniciativas de ley

Nóminas

Actas o minutas de las

comisiones

\section{Órganos Procesos electorales 6 años \\ autónomos \\ Procedimientos $\quad 3$ años \\ administrativos \\ 3 años}

Expedientes académicos

Finalmente, para el Poder Judicial se estableció un ciclo vital de los documentos compuesto de la siguiente manera:

Archivo de Trámite: $\quad 2$ años

Archivo de Concentración: 2.5 a 10 años

Archivo Histórico: $\quad 10$ años 
Con base en esta estructura, se estipuló que tanto las resoluciones, como los expedientes originales, por su trascendencia serían transferidos directamente al Archivo histórico una vez que hubiesen perdido su vigencia administrativa. Lo mismo debía ocurrir con los documentos relacionados con el ejercicio presupuestal de los partidos políticos.

\section{Conclusiones}

Como podemos observar, los esfuerzos han sido muchos y constantes, sin embargo, aún quedan asuntos pendientes, entre ellos, el de que faltan aún algunas Entidades, principalmente del norte fronterizo, como son los casos de Baja California Norte, Chihuahua, Sinaloa, Durango, Nuevo León, Tamaulipas y Campeche, en crear sus propias leyes que rijan el funcionamiento de sus Archivos.

En el siguiente mapa de la República Mexicana se muestran los Estados que ya cuentan con una ley de esta naturaleza, ya sea de las que hemos denominado en un artículo anterior como de primera generación, o bien, las que decidieron hacerlo en lo que llamamos en este artículo leyes de segunda generación. 


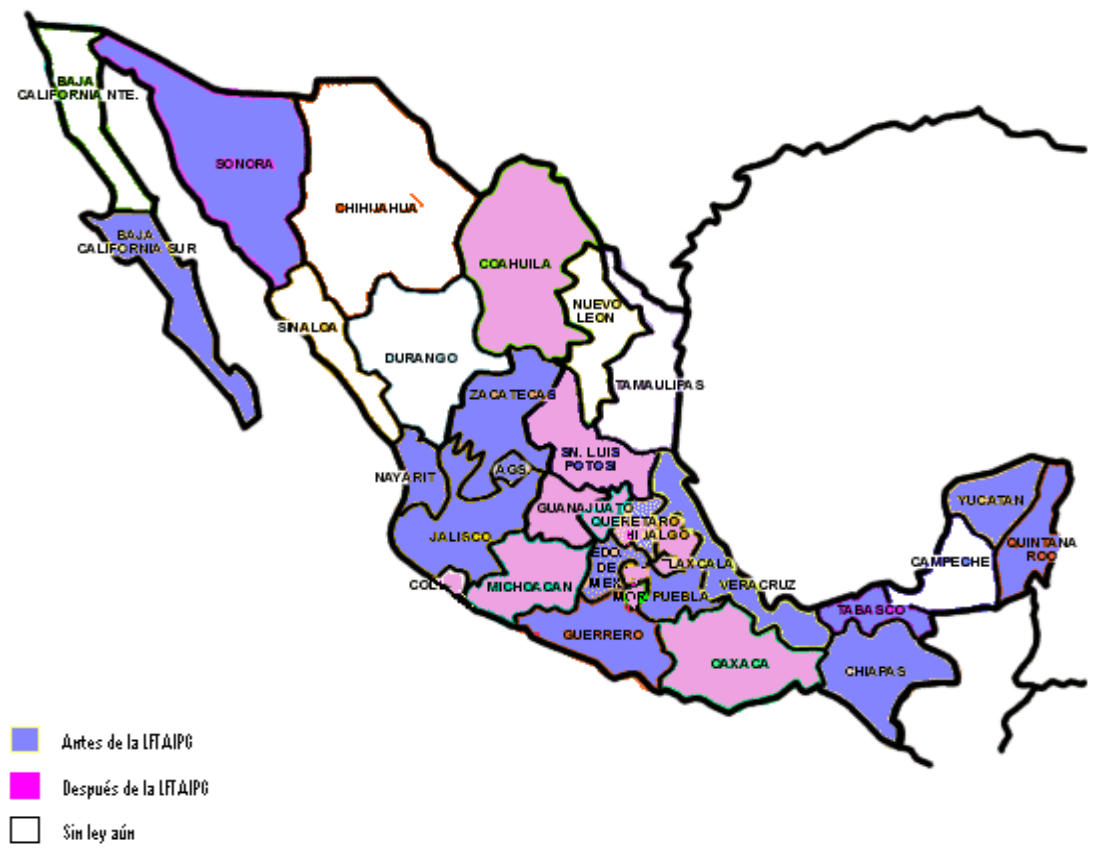

Pero sobre todo, se echa de menos una evaluación a detalle para conocer los beneficios y los inconvenientes que se han originado como consecuencia de la aplicación de las leyes ya publicadas.

\section{Bibliografía}

Asamblea del Distrito Federal. (8 de Octubre de 2008). Ley de archivos del Distrito Federal. Gaceta Oficial del Distrito Federal. Distrito Federal, México: Asamblea del Distrito Federal.

H. Congreso del Estado de Coahuila. (25 de Mayo de 2007). Ley de archivos públicos para el Estado de Coahuila. Periódico Oficial del Estado de Coahuila. Coahuila, México: Gobierno del Estado de Coahuila. 
H. Congreso del Estado de Colima. (9 de Mayo de 2009). Ley de archivos del Estado de Colima. Periódico Oficial del Estado de Colima. Colima, México: Gobierno del Estado de Colima.

H. Congreso del Estado de Guanajuato. (15 de Junio de 2007). Ley de archivos generales del Estado y los Municipios de Guanajuato. Periódico Oficial del Estado de Guanajuato. Guanajuato, México: Gobierno del Estado de Guanajuato.

H. Congreso del Estado de Hidalgo. (7 de Mayo de 2007). Ley de archivos del Estado de Hidalgo. Periódico Oficial del Estado de Hidalgo. Hidalgo, México: Gobierno del Estado de Hidalgo.

H. Congreso del Estado de Michoacán. (3 de Marzo de 2004). Ley de archivos administrativos e históricos del Estado de Michoacán. Periódico Oficial del Estado de Michoacán. Michoacán, México: Gobierno del Estado de Michoacán.

H. Congreso del Estado de Morelos. (16 de Septiembre de 2009). Ley estatal de documentación y archivos de Morelos. Periódico Oficial del Estado de Morelos. Morelos, México: Gobierno del Estado de Morelos.

H. Congreso del Estado de Oaxaca. (19 de Julio de 2008). Ley de archivos del Estado de Oaxaca. Periódico Oficial del Estado de Oaxaca. Oaxaca, México: Gobierno del Estado de Oaxaca.

H. Congreso del Estado de Querétaro. (24 de Julio de 2009). Ley de archivos del Estado de Querétaro. Periódico Oficial del Estado de Querétaro. Querétaro, México: Gobierno del Estado de Querétaro.

H. Congreso del Estado de San Luis Potosí. (18 de Octubre de 2007). Ley de transparencia administrativa y acceso a la información pública del Estado, Ley de protección de datos personales para el Estado, Ley de archivos administtrativos del Estado y Municipios y Ley de archivos para el Estado. Periódico Oficial del Estado de San Luis Potosí. San Luis Potosí, México: Gobierno del Estado de San Luis Potosí. 
H. Congreso del Estado de Tlaxcala. (17 de Diciembre de 2003). Ley de archivos del Estado de Tlaxcala. Periódico Oficial del Estado de Tlaxcala. Tlaxcala, México: Gobierno del Estado de Tlaxcala. 